\section{Effects of different lysis buffers of nucleic acid purification kit on the stability of influenza virus RNA}

\author{
Hongbo Liu* ${ }^{* 1,2}$, Yan Gan 3 , Yanheng Wu'², Hui Weng ${ }^{4}$, Ping Lei ${ }^{*, 4} \&$ Guanxin Shen ${ }^{4}$
}

\begin{abstract}
Aims: Under suboptimal storage and transport conditions, influenza virus (flu-v) RNA is prone to degradation and lysis buffers from RNA extraction kits have a potential to stabilize RNA. The aim of this study was to investigate the effects of different lysis buffers on the stability of flu-v RNA. Materials \& methods: Aliquots of flu-v suspension were processed in parallel with two lysis buffers, and then underwent cyclic freeze-thaw or prolonged storage at 4,22 and $-20^{\circ} \mathrm{C}$. The viral RNA was analyzed by using real-time and conventional RT-PCR amplifying, respectively, partial and full-length sequences of the flu-v matrix gene. Results: The viral RNA remained intact in samples treated with either of the two lysis buffers for at least 7 days at $4^{\circ} \mathrm{C}, 90$ days at $-20^{\circ} \mathrm{C}$ or following seven freeze-thaw cycles, but buffer A was superior to buffer $B$ in protecting RNA from degradation at $4^{\circ} \mathrm{C}$ and $22^{\circ} \mathrm{C}$, or following a further increase of freeze-thaw cycles. Conclusion: Lysis buffer preservatives provide viral RNA stabilization, whereas different lysis buffers vary in their ability to stabilize viral RNA, and thus their performance characteristics should be evaluated prior to their application in clinical practice.
\end{abstract}

Nucleic acid (NA)-based techniques are now widely used in influenza surveillance and diagnosis $[1,2]$. However, suboptimal storage and transport conditions of influenza virus (flu-v) samples will most likely result in viral RNA degradation [3-5], and in some settings it is difficult to ensure certain sample conditions required by WHO, such as ultra-low-temperature freezing, especially for resource-limited areas; consequently, the efficacy of the NA-based assays will be compromised. Thus, inexpensive, simple and efficient sample stabilization methods need to be developed for facilitating flu surveillance and diagnosis.

Earlier studies have shown that lysis buffers of NA extraction kits have the potential to be used as RNA stabilization agents at adverse temperatures and over an extended period of time [6,7], and have potential to inactivate viruses completely $[8]$, which would reduce the biohazard risk from sample leakage during transit and simplify transportation requirements while preserving the integrity of viral RNA before testing. Nevertheless, these studies did not give a comprehensive picture of the abilities of lysis buffers in protecting viral RNA from degradation and there are still some questions that remain unanswered. First, could intact viral RNA be recovered from the samples preserved in lysis buffer at adverse temperatures and over an extended period of time, considering that a real-time RT-PCR (rRT-PCR) targeting a shorter fragment was only employed to evaluate the presence, quantity and/or quality of viral RNA in these studies [6,7]? Second, what is the consequence of virus samples preserved in lysis buffer and subjected to repeated freeze-thaw cycles,

'Department of Laboratory Medicine, Affiliated Hospital of Guilin Medical University, Guilin, China

2Virology Laboratory, Center for Disease Control and Prevention of Zhongshan, Zhongshan, China

${ }^{3}$ Neuroimmunology Laboratory, Barrow Neurological Institute, St Joseph's Hospital and Medical Center, Phoenix, AZ, USA

${ }^{4}$ Department of Immunology, Tongji Medical College, Huazhong University of Science \& Technology, Wuhan, China

*Authors for correspondence: flood.001@163.com; adaleip@sina.com

\section{KEYWORDS}

- biological preservation

- buffer • freezing

- guanidine • influenza A

virus $\bullet$ reverse transcriptase polymerase chain reaction

- RNA stability • specimen

handling $\bullet$ temperature

- time factors • viral RNA 
a frequently encountered problem during subsampling and sample transport? Finally, do different lysis buffers have an identical ability to stabilize viral RNA?

To address the aforementioned questions, we examined the abilities of two lysis buffers from two methodologically different purification kits, buffer A from the Maxwell ${ }^{\circledR} 16$ Viral Total Nucleic Acid Purification Kit (Promega, WI, USA), and buffer B from QIAamp Viral RNA Mini Kit (Qiagen, Germany), to stabilize flu samples that underwent cyclic freeze-thaw or prolonged storage at specific temperatures. The relative quantity of flu-v RNA was determined by a rRT-PCR, and the integrity of flu-v RNA was assessed using a conventional RT-PCR (cRT-PCR) to detect the full-length matrix gene (entire RNA segment 7) of flu-v.

\section{Materials \& methods}

\section{- Virus preparation}

A pandemic H1N1 isolate A/Zhongshan/ SWL02/2009 (H1N1) was propagated and titrated in Madin-Darby canine kidney cells according to the WHO manual [9]. The virus culture supernatant was diluted in viral transport medium and the resulting low titer of virus containing $0.7 \log 50 \%$ tissue culture infective doses per $\mathrm{ml}$ was used for the experiments below.

\section{- Handling \& storage of virus samples}

The virus samples were processed in parallel with buffer $A$ and buffer B, as per the respective manufacturer's directions. Briefly, $200 \mu \mathrm{l}$ aliquots of the virus preparation were added to $1.5 \mathrm{ml}$ microcentrifuge tubes preloaded with aliquots of the freshly prepared buffer A ( $200 \mu$ lysis buffer plus $20 \mu \mathrm{l}$ proteinase $\mathrm{K}$ solution), the mixtures were vortexed for $10 \mathrm{~s}$, and then incubated at $56^{\circ} \mathrm{C}$ for $10 \mathrm{~min}$ to ensure that potentially infectious agents and RNases were inactivated before storage and transport. Similarly, $140 \mu$ l aliquots of the virus preparation were mixed by vortex for 15 $s$ with aliquots of the buffer B $(560 \mu \mathrm{l}$ buffer AVL plus $5.6 \mu \mathrm{l}$ carrier RNA solution $[1.0 \mu \mathrm{g} / \mu \mathrm{l}])$, and the mixtures were left at room temperature for $10 \mathrm{~min}$. To evaluate the effects of different lysis buffers on the samples experiencing time at certain temperatures, the treated samples were kept at three easily accessible temperatures: room temperature $\left(22 \pm 3^{\circ} \mathrm{C}\right)$ for 3 and 7 days, $4^{\circ} \mathrm{C}$ and $-20^{\circ} \mathrm{C}$ for $7,15,30,45,90$ and 160 days. For freeze-thaw study, the treated samples were frozen at $-70^{\circ} \mathrm{C}$ and thawed at room temperature for zero (for baseline samples) to 20 cycles; at each designated time point or freeze-thaw cycle, duplicate samples of each preservation method were collected and stored at $-70^{\circ} \mathrm{C}$ until analysis.

\section{- Viral RNA extraction}

All samples were extracted according to the respective manufacturer's instructions beginning with the step immediately following the 10 min incubation period. The samples treated with buffer A were extracted with the Maxwell 16 System and eluted in $50 \mu \mathrm{l}$ nuclease-free water. The samples treated with buffer B were extracted with the QIAamp Kit and eluted in $60 \mu \mathrm{l}$ Buffer AVE (Qiagen). Although having different starting and elution volumes $(200-\mu \mathrm{l}$ input and $50-\mu \mathrm{l}$ output vs $140-\mu \mathrm{l}$ input and $60-\mu$ l output), the two extraction methods in conjunction with either of the two RT-PCR assays below exhibited close detection limits $\left(\sim 10^{-0.3} \mathrm{TCID}_{50} / \mathrm{ml}\right.$ of the virus) according to our previous study [10] and the preliminary experiments in this study $[\mathrm{Liu} \mathrm{H}$, Wu Y, Unpublished Data].

\section{- RT-PCR assay}

All samples were tested by both rRT-PCR and cRT-PCR. The CDC Flu A rRT-PCR protocol [11] was used to detect a 106-nt fragment in the matrix gene of flu A virus. The assay was carried out on an ABI 7500 Fast System with the Superscript III Platinum One-step qRT-PCR kit (Invitrogen). ROX reference dye was added at a final concentration of $50 \mathrm{nM}$ to normalize the fluorescent reporter signal. The obtained threshold cycle $(\mathrm{Ct})$ value was used as a measure of relative quantity of flu-v RNA in samples. Flu-v RNA integrity was assessed by the cRT-PCR analysis of the complete matrix gene (1027 nt) of flu A virus with the primer set (MF1: 5'-AGCAAAAGCAGGTAGATATTGAAAGA-3'; MR1027: 5'-AGTAGAAACAAGGTAGTTTTTTACTC-3') developed by London WHOCC [12]. The reaction mixture of $25-\mu \mathrm{l}$ contains 1×QIAGEN OneStep RT-PCR buffer, $400 \mu \mathrm{M}$ each dNTP, $1 \mu \mathrm{l}$ QIAGEN OneStep RT-PCR Enzyme mix, 10 U RNase inhibitor (ABI), $0.5 \mu \mathrm{M}$ each primer and $5 \mu \mathrm{l}$ RA template. The amplification was performed on a DNA thermal cycler (GeneAmp PCR System 9600; Perkin-Elmer, CA, USA) using the following conditions based on the manufacturer's instructions: $50^{\circ} \mathrm{C}$ for $30 \mathrm{~min}, 95^{\circ} \mathrm{C}$ for $15 \mathrm{~min}$, then 40 cycles of $94^{\circ} \mathrm{C}$ for $30 \mathrm{~s}, 55^{\circ} \mathrm{C}$ for $30 \mathrm{~s}$ and $72^{\circ} \mathrm{C}$ for $1.5 \mathrm{~min}$, followed by $72^{\circ} \mathrm{C}$ for 
$10 \mathrm{~min}$. PCR products were electrophoresed in a $1.5 \%$ agarose gel in $0.5 \times \mathrm{TBE}$ buffer $(45 \mathrm{mM}$ Tris-borate, $1 \mathrm{mM}$ sodium EDTA), stained with GoldView Nucleic Acid Stain (SBS Genetech, China), and photographed with ZF-258 Gel imaging system (Jiapeng Ltd., China). Samples with discrepant results were retested in duplicate.

\section{Results}

The mean Ct values of the baseline samples were 29.6 and 30.1, respectively, for the Maxwell 16 System and QIAamp extraction methods, and the respective standard deviation (SD) was 0.5 and 0.6, which was in accordance with our previous study [10]. It was considered to be a significant change in RNA yield when a mean $\mathrm{Ct}$ value goes beyond the possible variation range (more or less than 1.96 SD) of the assay method by comparison with the corresponding baseline value.

At $-20^{\circ} \mathrm{C}$, an unchanged quantity of viral RNA was detected by the rRT-PCR for at least 90 days and the complete matrix gene was amplified successfully for the whole observation period from the virus samples treated with either of the two lysis buffers (Table 1). At 4 and $22^{\circ} \mathrm{C}$, flu-v RNA was relatively more stable when kept in buffer $\mathrm{A}$ than kept in buffer B. At $4^{\circ} \mathrm{C}$, the variation of $\mathrm{Ct}$ values was within the accepted \pm 1.96 SD interval for buffer A-stored samples maintained for 45 days, while buffer B stored samples for 30 days, and the full-length matrix gene could be obtained from buffer A-stored samples up to 90 days while not from buffer B-stored samples at 15 days (Table 1). At $22^{\circ} \mathrm{C}$ on day 7 , buffer A preservation resulted in less than a tenfold reduction in the level of flu-v RNA, whereas buffer B preservation resulted in an approximate 100 -fold reduction in the level of flu-v RNA, although neither of them allowed the reproducible recovery of full-length matrix gene (Table 1).

The virus samples treated with either of the two lysis buffers did not show a decline in the viral RNA quantity and integrity after seven cycles of freeze-thaw (Table 2 \& Figure 1). To observe whether the two lysis buffers differ in their ability to confer protection, freeze-thaw was carried out up to 17-20 cycles for the bufferpreserved samples. The results showed that, after additional freeze-thaw cycles, the virus samples still did not show significant change in $\mathrm{Ct}$ values (Table 2) and the entire matrix gene could be recovered (Figure 1). However, the buffer B-treated samples after 17 freeze-thaw cycles produced visibly much darker full-length amplicon bands than those samples within seven free-thaw cycles (Figure 1). By contrast, the buffer A-treated samples experienced 20 freeze-thaw cycles still provided as bright amplicon bands as baseline samples (Figure 1).

\section{Discussion}

The use of lysis buffers of NA isolation kits for stabilizing viral RNA has been investigated by Anwar et al. [6], who found that viral RNA integrity assessed by rRT-PCR was maintained for at least 5 days at $25^{\circ} \mathrm{C}$ when samples were stored in lysis buffer, and by Blow et al. [7], who found that viral RNA recovered from lysis buffer-stabilized samples was suitable for detection by rRT-PCR for up to 35 days at $4^{\circ} \mathrm{C}$ and $-20^{\circ} \mathrm{C}$, but degraded rapidly at room temperature and $32^{\circ} \mathrm{C}$. Similar results were obtained in our study that, when analyzed by rRT-PCR, viral RNA from lysis buffer-stored samples did not show a significant reduction in relative yield within at least 30 days at $4^{\circ} \mathrm{C}$ and within 90

Table 1. Effects of different lysis buffers on the stability of influenza virus RNA after a period of storage at different temperatures.

\begin{tabular}{|c|c|c|c|c|c|c|c|c|c|c|c|c|c|c|}
\hline \multirow{3}{*}{$\begin{array}{l}\text { Analytic method } \\
\text { and treatment } \\
\text { buffer }\end{array}$} & \multicolumn{14}{|c|}{ Incubation time (days) } \\
\hline & \multicolumn{2}{|c|}{$22^{\circ} \mathrm{C}$} & \multicolumn{6}{|c|}{$4^{\circ} \mathrm{C}$} & \multicolumn{6}{|c|}{$-20^{\circ} \mathrm{C}$} \\
\hline & 3 & 7 & 7 & 15 & 30 & 45 & 90 & 160 & 7 & 15 & 30 & 45 & 90 & 160 \\
\hline \multicolumn{15}{|l|}{ Real-time RT-PCR } \\
\hline Buffer A & $31.4^{+}$ & 32.4 & 29.2 & 30.0 & 30.1 & 30.0 & 31.1 & 34.2 & 30.6 & 30.6 & 29.1 & 29.5 & 30.5 & 31.3 \\
\hline Buffer B & 33.0 & 36.0 & 29.9 & 31.0 & 30.9 & 32.1 & 34.3 & 38.1 & 30.6 & 30.2 & 30.2 & 30.0 & 30.1 & 31.9 \\
\hline \multicolumn{15}{|c|}{ Conventional RT-PCR } \\
\hline Buffer A & $+/-^{\ddagger}$ & $-1-$ & $+/+$ & $+/+$ & $+/+$ & $+/+$ & $+/-$ & $-1-$ & $+/+$ & $+/+$ & $+/+$ & $+/+$ & $+/+$ & $+/+$ \\
\hline Buffer B & $-/-$ & $-1-$ & $+/+$ & $-1-$ & $-1-$ & $-1-$ & $-1-$ & $-1-$ & $+/+$ & $+/+$ & $+/+$ & $+/+$ & $+/+$ & $+/+$ \\
\hline
\end{tabular}

Duplicate samples with discrepant results were retested in duplicate, and a sample was deemed positive or negative when at least two of three results were the same. A plus $(+)$ represents a positive reaction and a minus (-) represents a negative reaction.

'Each represents a mean Ct value of duplicate samples assayed by real-time RT-PCR.

tResults of duplicate samples assayed by conventional RT-PCR were reported as Experiment 1/Experiment 2. 
Table 2. Effect of cyclic freeze-thaw on the real-time RT-PCR detection of a 106-nucleotide segment in the matrix gene of influenza A virus from samples treated with different lysis buffers.

\begin{tabular}{|c|c|c|c|c|c|c|c|c|c|c|c|c|}
\hline \multirow[t]{2}{*}{ Lysis buffer } & \multicolumn{12}{|c|}{ Mean Ct } \\
\hline & FT-0 & FT-1 & FT-2 & FT-3 & FT-4 & FT-5 & FT-6 & FT-7 & FT-17 & FT-18 & FT-19 & FT-20 \\
\hline Buffer A & $29.6^{+}$ & 29.3 & 29.4 & 29.5 & 29.4 & 29.5 & 29.2 & 29.9 & 30.1 & 29.8 & 29.7 & 29.4 \\
\hline
\end{tabular}

days or longer at $-20^{\circ} \mathrm{C}$, but decreased notably on day 7 at room temperature. However, rRTPCR assay used only to assess RNA integrity might not reveal the truth since it tolerates partial degradation of RNA [13,14]. This was demonstrated by our results that the entire matrix gene was not amplified from some samples (e.g., those preserved in buffer $\mathrm{B}$ at $4{ }^{\circ} \mathrm{C}$ for $15-45$ days) whose viral RNA concentration indicated by $\mathrm{Ct}$ values was well within the detection limit of the cRT-PCR assay. The requirement for RNA integrity rises as amplicon length increases $[13,15]$. In some cases, the obtaining of full-length genomic RNA of flu-v is needed for subtype identification and genetic analysis [16-18]. Therefore, at least one full-length gene in eight segmented genes of flu-v should be amplified in assessment of the integrity of preserved flu-v RNA. According to the results of cRT-PCR assay, intact viral RNA molecules could be recovered from lysis buffer-preserved samples for up to 160 days at $-20^{\circ} \mathrm{C}$ and for 1 week or longer at $4^{\circ} \mathrm{C}$, while they were almost degraded into short pieces on day 3 at room temperature.

A previous study [19] has demonstrated the freeze-thaw damage to flu-v RNA, in which the amount of flu-v RNA decreased with the increase of freeze-thaw cycle and declined significantly after four freeze-thaw cycles. RNAlater, a commercial RNA stabilization reagent, could reduce the deterioration of viral RNA under various transport conditions including multiple freeze-thaw cycles $[3,15]$; however, its use adds extra costs and steps to virus sample processing and maintains viral infectivity, which increases the risk of biohazard exposure [20]. Lysis buffer of NA extraction kit has the potential to be used as an RNA stabilization agent $[6,7]$, but its ability to protect viral

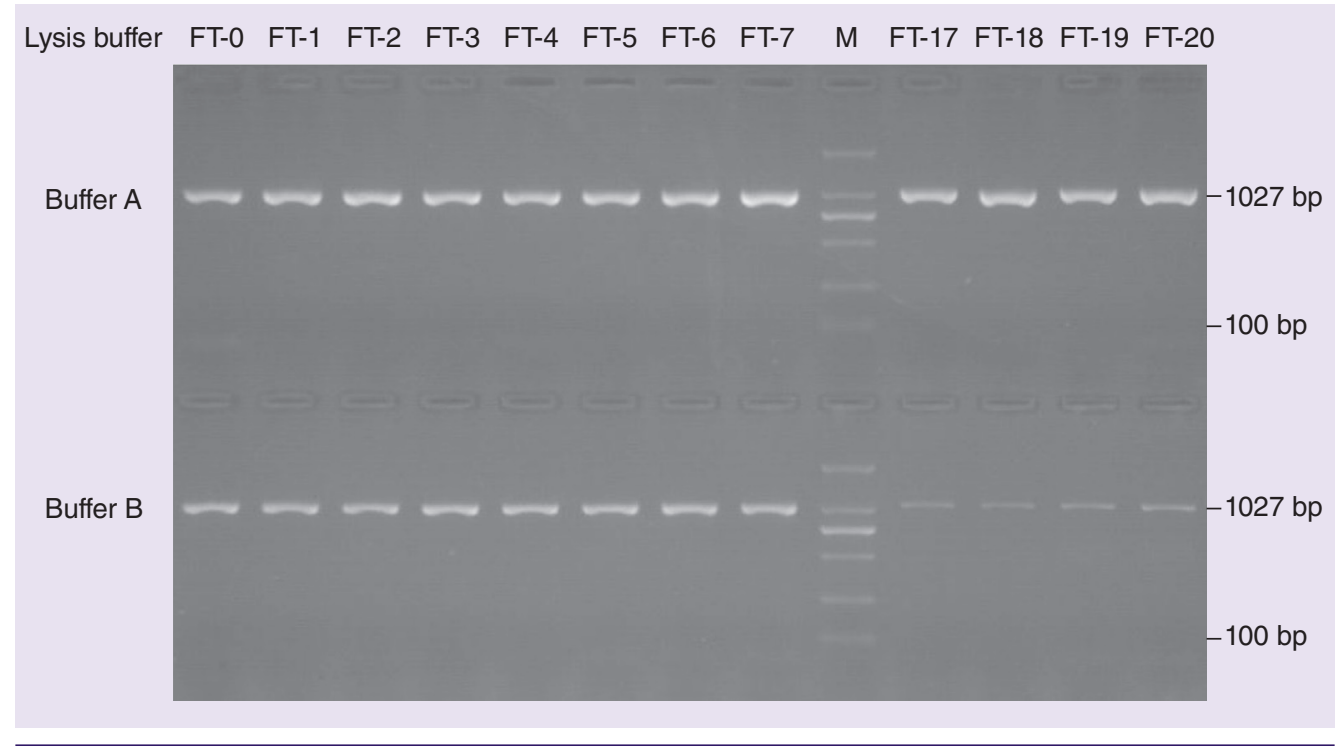

Figure 1. Effect of cyclic freeze-thaw on the conventional RT-PCR amplification of the entire matrix gene (1027 nt) of influenza A virus from samples treated with different lysis buffers. The results presented here are from one of duplicate samples that showed similar result profiles. Eight of 25- $\mu$ l amplification products were electrophoresed in a 1.5\% agarose gel in $0.5 \times$ TBE buffer. FT: Freeze-thaw; M: DNA molecular marker (DL2,000 DNA Marker, TAKARA Inc). 
RNA from freeze-thaw damage has not been assessed and reported. In this paper, the result that flu-v RNA in the presence of either of two lysis buffers did not deteriorate in quality and quantity within seven freeze-thaw cycles suggests that the lysis buffers could confer flu-v RNA protection against freeze-thaw damage similar to that by RNAlater solution.

The two lysis buffers used in this study were demonstrated to have similar ability in preventing RNA degradation at $-20^{\circ} \mathrm{C}$ or within seven cycles of freeze-thaw, whereas buffer $\mathrm{A}$ was superior to buffer $\mathrm{B}$ at $4^{\circ} \mathrm{C}$ and $22^{\circ} \mathrm{C}$, or following the increase of freeze-thaw cycles. That the two solutions differed in their abilities might result from their different compositions, although both are known to contain chaotropic salts that denature proteins and other ingredients that inhibit RNase activity. For example, the carrier RNA in the buffer $B$, but not in the buffer A, could enhance the recovery of viral RNA by the QIAamp method when added to Buffer AVL. However, the carrier RNA itself when dissolved is prone to degradation under adverse conditions such as ambient temperature and extended incubation at $2-8^{\circ} \mathrm{C}$, which would lead to reduced recovery of viral RNA [21].

There are two limitations in this study. The first is that virus cultures instead of various clinical samples were used. Some of the latter are more complex in composition than the former. For this reason, a low virus titer was used in our study in order to easily observe qualitative change of the viral RNA even if suffering slight damage. Additionally, the cultures might also be rich in RNase from the disrupted cells. These may in part compensate this limitation. The second limitation in this study is that only two lysis buffers were examined. Therefore, further evaluations will help to consolidate the results of this study, in which samples from diverse sources should be employed to simulate real circumstances, and more comparisons should be made with other lysis buffers and/or a commercial RNA stabilizer such as RNAlater.

In spite of the above limitations, flu-v RNA remained intact in lysis buffer-treated samples for at least 7 days at $4^{\circ} \mathrm{C}, 90$ days at $-20^{\circ} \mathrm{C}$ or seven freeze-thaw cycles, supporting the use of lysis buffer as an RNA stabilizer at suboptimal

\section{EXECUTIVE SUMMARY}

\section{Background}

- Lysis buffer has the potential to be used as an RNA stabilization agents, but some questions remained unanswered.

- Two lysis buffers were examined to evaluate their ability in stabilizing influenza viral RNA.

\section{Methods}

- Influenza samples treated with lysis buffers underwent prolonged storage at suboptimal temperatures or cyclic freeze-thaw.

- The viral RNA was assayed by both real-time RT-PCR and conventional RT-PCR.

\section{Results}

- Entire matrix gene of influenza virus could be recovered from lysis buffer-treated samples after prolonged storage at suboptimal temperatures $\left(4^{\circ} \mathrm{C}\right.$ and $\left.-20^{\circ} \mathrm{C}\right)$.

- Influenza viral RNA remained intact in lysis buffer-treated samples that underwent seven cycles of freeze-thaw.

- Influenza viral RNA was relatively more stable when kept in buffer A than kept in buffer B.

\section{Discussion}

- Lysis buffers enable viral RNA to withstand the deleterious effect of cyclic freeze-thaw and prolonged storage at suboptimal temperatures.

- Different lysis buffers varied in their abilities to stabilize viral RNA, and thus lysis buffers should be validated for their performance characteristics prior to their application in clinical practice.

- Further evaluations will help to consolidate the results of this study, in which samples from diverse sources should be employed to simulate real circumstances, and more comparisons should be made with other lysis buffers and/or a commercial RNA stabilizer such as RNAlater. 
temperatures $\left(4^{\circ} \mathrm{C}\right.$ and $\left.-20^{\circ} \mathrm{C}\right)$ or when freezethaw exposure of samples is hard to avoid. However, different lysis buffers vary in their ability to stabilize viral RNA, suggesting that lysis buffers should be validated for their performance prior to their application in clinical practice.

\section{Future perspective}

The use of lysis buffer as preservative has many advantages, such as being simple and inexpensive due to needing no extra reagent and procedure for the downstream purification of target RNA. These advantages will promote more research on the performance of different lysis buffers for sample preservation and transport in different application environments, which will thus facilitate widespread application of lysis buffer in clinical practice.

\section{Financial \& competing interests disclosure}

This research was supported by the State Project on Major Infectious Diseases Prevention (2012ZX10002006-003) and Program for Changjiang Scholars and Innovative Research Team in University (grant no. IRT1131). The authors have no other relevant affliations or financial involvement with any organization or entity with a financial interest in or financial conflict with the subject matter or materials discussed in the manuscript apart from those disclosed.

No writing assistance was utilized in the production of this manuscript.

\section{Open access}

This work is licensed under the Creative Commons Attribution-NonCommercial 3.0 Unported License. To view a copy of this license, visit http://creativecommons.org/ licenses/by-nc-nd/3.0/

RecommendationsH1N1_20090521. pdf?ua $=1$

13 Fleige S, Pfaffl MW. RNA integrity and the effect on the real-time qRT-PCR performance. Mol. Aspects Med. 27(2-3), 126-139 (2006).

- RNA quantitation by real-time RT-PCR tolerates partial degradation of RNA.

14 Schoor O, Weinschenk T, Hennenlotter J et al. Moderate degradation does not preclude microarray analysis of small amounts of RNA. Biotechniques 35(6), 1192-1196, 1198-1201 (2003).

8 Blow JA, Dohm DJ, Negley DL, Mores CN. Virus inactivation by nucleic acid extraction reagents. J. Virol. Methods 119(2), 195-198 (2004).

9 WHO. Manual for the laboratory diagnosis and virological surveillance of influenza (2011).

http://whqlibdoc.who.int/ publications/2011/9789241548090_eng. pdf?ua $=1$

10 Liu H, Gan Y, Yang B et al. Performance evaluation of the Maxwell 16 System for extraction of influenza virus RNA from diverse samples. PLoS ONE 7, e48094 (2012).

11 WHO. CDC protocol of real time RTPCR for influenza A (H1N1) (2009).

http://www.who.int/csr/resources/ publications/swineflu/ CDCRealtimeRTPCR SwineH1Assay-2009_20090430.pdf?ua=1

12 WHO. WHO information for laboratory diagnosis of pandemic (H1N1) 2009 virus in humans - revised (2009).

http://www.who.int/csr/resources/ publications/swineflu/WHO_Diagnostic_
- RNA quantitation by real-time RT-PCR tolerates partial degradation of RNA.

15 Evers DL, Slemons RD, Taubenberger JK. Effect of preservative on recoverable RT-PCR amplicon length from influenza A virus in bird feces. Avian Dis. 51(4), 965-968 (2007).

-. The requirement for RNA integrity rises as amplicon length increases, and guanidine and commercial buffers provide viral RNA stabilization.

16 Ghedin E, Laplante J, DePasse J et al. Deep sequencing reveals mixed infection with 2009 pandemic influenza A (H1N1) virus strains and the emergence of oseltamivir resistance. J. Infect. Dis. 203(2), 168-174 (2011).

17 Inoue E, Wang X, Osawa Y, Okazaki K. Full genomic amplification and subtyping of influenza A virus using a single set of universal primers. Microbiol. Immunol. 54(3), 129-134 (2010).

18 Nelson MI, Tan Y, Ghedin E et al. Phylogeography of the spring and fall waves 
of the H1N1/09 pandemic influenza virus in the United States. J. Virol. 85(2), 828-834 (2010).

Ward CL, Dempsey MH, Ring CJ et al. Design and performance testing of quantitative real time PCR assays for influenza A and B viral load measurement. J. Clin. Virol. 29(3), 179-188 (2004).

-• Detrimental effect of cyclic freeze-thaw on influenza virus RNA.

20 Uhlenhaut C, Kracht M. Viral infectivity is maintained by an RNA protection buffer. J. Virol. Methods 128(1-2),189-191 (2005).

21 Qiagen. QIAamp Viral RNA Mini Handbook (3rd Edition). Qiagen, Hilden, Germany (2010). 